\title{
“How do you do it?”: MSW Field Director Survey
}

\author{
Bruce Dalton \\ Laura Stevens \\ Jane Maas-Brady
}

\begin{abstract}
This paper reports on a survey of MSW field directors in the United States. Results indicate that in some areas there is similarity between field programs, such as field training and orientation, and the student placement process. There was great variety between field programs in the areas of student field requirements, student field credits, and field liaison faculty status. Most field programs report adequate resources but a significant minority report a lack of resources. The benefits of increasing specificity of mandated standards at the cost of lessened program flexibility is discussed.
\end{abstract}

Keywords: Field seminar, field placement, MSW field program

\section{INTRODUCTION}

Social work field instruction has evolved from an apprenticeship model early in its history to an educationally-focused model in which experienced professionals are selected as field instructors to help students achieve the educational objectives of the field program (Bogo, 2005; Frumkin \& Lloyd, 1995). The field experience is where and when students connect the theoretical concepts learned in the classroom with the practical aspects of service provision while also gaining an appreciation for the breadth and depth of the many roles that a social worker performs. This approach is compatible with John Dewey's philosophy of progressive education in which students learn by doing (Scannell \& Simpson, 1996). Dewey believed having relevant experience in the wider world brought value and purpose to what goes on in the classroom. According to the Educational Policy and Accreditation Standards (EPAS) of the Council on Social Work Education (CSWE) field instruction is now seen as the signature pedagogy of social work (EPAS, CSWE, 2008). CSWE is the accrediting body for social work programs in the United States. Signature pedagogy is defined as "the central form of instruction and learning in which a profession socializes its students to perform the role of practitioner" and its purpose is to "connect the theoretical and conceptual contribution of the classroom with the practical world of the practice setting” (EPAS, 2.3, CSWE, 2008).

Though the field practicum is considered the signature pedagogy, it is the experience and observation of the authors that many field practicum personnel enter the area of social work field education with no specific training on how to be a field instructor, liaison, coordinator, or director. There is also little information available about how the field component is implemented which may serve as a guide to those directing or forming a field program. It is the purpose of this study to provide a nation-wide overview of how MSW field programs are structured, the process by which students are placed in practicum settings, how field instructor orientation and training are provided, and the

Bruce Dalton, Ph.D., is an Associate Professor in the Department of Social Work at East Tennessee State University in Johnson City, TN. Laura Stevens, Ph.D., has no current academic affiliation. Jane Maas-Brady, MSW, is Director of Field in the Department of Social Work at East Tennessee State University.

Copyright (c) 2011 Advances in Social Work Vol. 12 No. 2 (Fall 2011), 276-288 
sufficiency of the resources that are allotted to field education. This will help fill the current gap in knowledge regarding the current state of field education in the U.S.

\section{LITERATURE REVIEW}

This literature review covers field program implementation, orientation and training, field standards, resources, and standardization. Program implementation refers to the structure that allows the program to exist in an educational bureaucracy. In some social work programs, field work offices maintain a high degree of autonomy, while in other schools field staff are closely integrated into the general program. Orientation and training encompasses the efforts of an institution's field staff to orient field instructors to the program requirements and to train field instructors to become social work educators and supervisors. As with program implementation, orientation and training efforts have the potential to vary widely from one school to the next. Field standards include the type, amount, and quality of activity required of students in their field placements. Although CSWE sets general requirements for the number of field hours and the types of activities appropriate for students, ultimately it is the responsibility of the individual field program to interpret those standards. Resources are the financial and structural support given to the field component in a social work department. Standardization is the degree of similarity between programs both in practice and in writing.

There have been few previous surveys of social work field directors in the U.S. that address program implementation. Kilpatrick and Holland (1993) surveyed 64 CSWE accredited schools that offered both MSW and BSW degrees. After investigating the management structure of field programs, they found that all but one reported having a position titled Director of Field Instruction even though the programs varied considerably in other aspects, such as other field staff available and faculty involvement as liaisons. Burke, Condon, and Wickell (1999) found in their sample of 66 social work programs that 38\% reported faculty members were field liaisons, and that all field liaisons (both faculty and other) made a mean average of 2.9 field visits per year. Ligon and Ward (2005) surveyed MSW field liaisons who reported a mean average of 2.2 field visits per semester. The most common recommendation for improvement of the liaison position noted by Ligon and Ward's respondents was to "Initiate more structure and create standards for field education” (p. 240). There were no national studies found that looked at how students proceed through the field placement process, though recommendations are made for the use of student and agency questionnaires to streamline and systematize the process (Brownstein,1989) and student interviews are also suggested when practicable (Zanville \& Markwood, 1982). It appears that in regard to program implementation and staffing, the only common denominator between the programs studied is the position of Field Director.

The number of field hours required within a practicum placement has not been explored on a national level, perhaps in part because CSWE sets a minimum standard of 900 hours. Raskin, Wayne, and Bogo (2008) found in the minutes of a May 1982 CSWE board meeting a verbal reference to a study of MSW programs that found a range of 682 to 2,142 hours spent in field with a mean average of 1,082 hours. This was prior to the 
standard set by CSWE of a minimum of 900 hours for MSW placement. Raskin et al. make the case that the current requirement of 900 hours was set arbitrarily and that there continues to be no empirical support for this or any other number being optimal. They advocate that the number of hours be adjusted to the individual student taking into consideration prior work experience. Although there is a minimum number of field hours now required in accredited programs, is there still such variability as found by Raskin et al.? If so, how does this variability impact the quality of a student's education and training?

Skolnik (1989) surveyed field directors at accredited BSW and MSW programs and found that $99 \%$ provided training for new field instructors and $71 \%$ did so for advanced field instructors. Of those who provided training, 31\% reported it was required for new field instructors and 20\% reported it was required for advanced instructors. McChesney (1999) received surveys from 92 MSW field directors and found 93.5\% offered field instructor orientation and $70.7 \%$ offered ongoing field training. Field orientation was offered but not mandated by 47 of the field directors, though many added that it was expected or strongly encouraged for new field instructors. Many of the field directors used incentives to encourage attendance, especially meals (41\%) and official CEU's (continuing education units) (38\%). McChesney recommends that CSWE provide guidance to programs on field instructor orientation, such as an orientation handbook or national standards. In Britain field instructors are required to be trained and certified by the national social work governing body (Rogers, 1996). No such requirement exists in the United States and there is not much guidance available for field directors to use when designing programs. In the U.S. neither field instructors nor placement agencies receive direct financial support from the government in support of the field placement, as is the case in Britain where agencies are compensated through the General Social Care Council when they accept field students.

Dettlaff and Dietz (2004) conducted focus groups with field instructors to identify their perceived training needs and identified particular areas of knowledge and skills that would be helpful for field instructor training, as well as a preference for a small group format for the training that would allow for the exchange of ideas. Berg-Weger, Rochman, Rosenthal, Sporleder, and Birkenmaier (2007) describe the process of how a group of three social work field programs collaborated to develop and oversee a joint field instructor training program. Although Berg-Weger et al. describe a replicable process for developing a field orientation and training program and curriculum, they do not provide that curriculum; other programs following this process would still be required to develop their own curriculum. There are but two training guides available that give concrete curriculum suggestions for field directors to use when providing field instructor education (Bogo \& Vayda, 1998; Detlaff, 2003). A national survey of 218 field directors at accredited BSW and MSW programs was conducted by Bedard (1998) and found 87\% agreed to strongly agreed that "The Council on Social Work Education should take some responsibility for field instructor training workshops that set some national standards for field instruction.”

The issue of resources both within and without the educational institution was found to impact the field component. The changing practice environment was found by Raskin 
and Blome (1998) to have impacted the availability of field placements. Responding field directors reported agencies were withdrawing as field placement sites due to reduced resources, increased caseloads, and staff who had to document their time as billable units. Ligon and Ward (2005) also found in their qualitative data a stated concern about the increasing impact of managed care shifting the emphasis onto billable units as an increasing pressure on field placement agencies. Bedard's (1998) survey included the item "There is a lack of institutional support for field instruction in the university" and found that 43\% agreed or strongly agreed. In McChesney's (1999) survey it was found that the problem most often cited by respondents was the lack of resources of time, budget, and staff. Skolnik (1989) found the third most common area cited by her respondents was "The lack of university support and appropriate administration for field education.” Respondents in Kilpatrick and Holland's (1993) field director survey cited a lack of resources as the most common problem in administering the field program.

Specific requirements for MSW field instruction are described in the Educational Policy and Accreditation Standards (EPAS, CSWE, 2008). These include specific "policies, criteria, and procedures for selecting field settings; placing and monitoring students; maintaining field liaison contacts with field education settings; and evaluating student learning and field setting effectiveness congruent with the program's competencies" (EPAS, M2.1.5, CSWE, 2008), and providing "orientation, field instruction training, continuing dialog with field education settings and field instructors" (EPAS, M2.1.7, CSWE, 2008). The specifics of how to fulfill these policy mandates are not specified; rather it is up to the individual program to determine how to implement them in a way that is most appropriate for their situation. This latitude is beneficial in that it allows each program to use discretion in planning an individual program that appropriately meets needs, but it leaves field programs with the challenge of designing and justifying their choices. Whenever such latitude is allowed in implementing policy, it opens a range of possibilities, including some that may be less than ideal (Lipsky, 1980). Raskin, Wayne, and Bogo (2008) recommend that field mandates be limited to those which can be empirically shown to be beneficial to students meeting their educational goals. For programs that seek guidance from other institutions there is not much information available on how other programs have implemented their field component.

The literature on social work field instruction indicates there is considerable variation in both how the field component is implemented and the standards that are applied to it. Further, there are gaps in knowledge of how the field component is implemented. This article will investigate and report how CSWE accredited MSW programs implement the above aspects of their field program. This study explores the following research questions: What are the common student field placement practices? How do field offices meet the CSWE requirement to provide field instructor orientation and training? How is the field component implemented (e.g. seminar characteristics, liaison visits)? This study also collects basic program data on aspects of the field component (e.g. size) that have not been previously examined. 


\section{METHODOLOGY}

A 29-item questionnaire using both closed and open-ended questions was developed to examine field instructor orientation and training, the student placement process, field seminars, and resources available to field programs. The questionnaire was reviewed by three current or former field directors for content and clarity. The questionnaire was mailed in September 2007 to field directors at all 204 MSW Programs with either accredited or candidacy status with CSWE as of August 2007. Follow-up mailings were sent to non-respondents in October 2007. Completed surveys were received from 135 field directors for a 66\% response rate which is considered good for a mailed survey (Rubin \& Babbie, 2001). Though the questions focused primarily on specifics about program structure and administration, the respondents were the field directors, thus the unit of analysis is considered to be the field director. For grammatical simplicity the results are often presented from the perspective of programs.

\section{RESULTS}

\section{Placement Process}

Asking students to fill out a questionnaire before placement is a common practice with $91 \%$ of field directors reporting doing so. Personal interviews with students require a greater time commitment for the field office field staff: $79 \%$ of the respondents reported that their offices conduct these interviews. The most common activity in the placement process is an interview with the field instructor, reported by $95 \%$ of the field directors. Four programs reported using neither a questionnaire nor an interview but three of these reported the field instructor held an interview with the student, leaving only one program reporting none of the three activities in their placement process (See Table 1).

Table 1. Student Placement Process

\begin{tabular}{lrrr}
\hline “Before student placement do you require...” & Yes (\%) & No (\%) & N \\
\hline Student questionnaire? & 91 & 9 & 128 \\
Interview with placement office? & 79 & 21 & 127 \\
Interview with field instructor? & 95 & 5 & 124 \\
\hline
\end{tabular}

\section{Orientation and Training}

Almost all field programs stressed field orientation and training. Ninety-eight percent offered field instructor orientation and $96 \%$ offered field instructor training. All programs reported offering one or the other. Although $60 \%$ responded that they require field instructors to attend orientation, only 26\% responded that there are consequences for not attending. Thirteen went on to report that those field instructors who do not attend orientation would not receive students. Field directors in five programs reported that field office personnel would visit the field instructors who do not attend orientation to provide 
the orientation, which places a greater burden on field office personnel. Similarly $60 \%$ responded that they require field instructors to attend training, but only $34 \%$ responded that there are consequences for not attending. Because of the high number of missing values for consequences of not attending orientation and/or training it is likely the percentages of programs having consequences is inflated (See Table 2).

\section{Table 2: $\quad$ Field Instructor Orientation and Training}

\begin{tabular}{lrrr}
\hline "Does your field office...” & Yes (\%) & No (\%) & $\mathrm{N}$ \\
\hline Offer field orientation? & 98 & 2 & 130 \\
Require attendance at orientation? & 61 & 39 & 128 \\
Have consequences for not attending orientation? & 26 & 74 & 96 \\
Offer field training? & 96 & 4 & 125 \\
Require attendance at training? & 60 & 40 & 126 \\
Have consequences for not attending training? & 34 & 66 & 77 \\
\hline
\end{tabular}

\section{Field Seminars}

Field seminars are reported as a component of $81 \%$ of field programs. These seminars are given academic credit separate from field hours at $38 \%$ of the field programs with seminars. In cases where academic credit is given separate from field hours the mean number of credits given is 1.8 with a range of $0.5(n=2)$ to $4(n=1)$. Field seminars meet between 1 and 16 times per semester with a mean of 9.5. The length of each seminar had a mean of two hours. One program reported conducting four seminar sessions during a semester, each session eight hours in length. The mean total number of seminar hours in a semester was 17.5 with a range of 1.5 to 45 . The number of liaison field visits required per semester ranged from zero to three with a mean of 1.5 (See Table 3).

\section{Table 3: $\quad$ Seminar and Placement Characteristics}

\begin{tabular}{lrrrr}
\hline & Mean & Range & S.D. & N \\
\hline Times seminar meets each semester. & 9.5 & $1-16$ & 4.74 & 106 \\
Hours each seminar meeting lasts. & 2 & $0.5-8$ & 0.96 & 104 \\
Total hours of seminar per semester. & 17.4 & $1.5-45$ & 9.63 & 104 \\
Credit hours for seminar if separate from field credits. & 1.8 & $0.5-4$ & .94 & 39 \\
Credit hours for total field placement. & 13.4 & $0-28$ & 4.79 & 123 \\
Clock hours for total field placement. & 1010 & $720-1380$ & 103.50 & 131 \\
Liaison field visits per semester. & 1.5 & $0-3$ & 0.67 & 131 \\
Ratio of students to field office FTE’s & $84: 1$ & $7: 1-625: 1$ & 72.90 & 129 \\
\hline
\end{tabular}




\section{Liaisons}

A slight majority of programs reported liaison work done primarily by full-time faculty, though many relied heavily on adjuncts (See Table 4). Of the 107 programs that had field seminars $72 \%$ reported that field liaisons were also seminar leaders, thus integrating the liaison work and the group processing function of the seminar. In cases where the liaisons were also seminar leaders the number of teaching credits awarded for the combined task varied from .5 to 6 credits $(M=2.7)$. In 17 cases liaisons were not also seminar leaders, and for being only a liaison they received one to three teaching credits per semester. In 16 cases seminar leaders were not also liaisons, and for being only a seminar leader they likewise received one to three teaching credits per semester.

\section{Table 4: $\quad$ Field Liaison Status}

\begin{tabular}{lcc}
\hline "Are your field liaisons...” & $\%$ & $\mathrm{~N}$ \\
\hline All full time faculty & 22.7 & 29 \\
Mostly full time faculty & 32.8 & 42 \\
Evenly split & 16.4 & 21 \\
Mostly adjuncts & 17.2 & 22 \\
All adjuncts & 10.9 & 14 \\
\hline Total & 100 & 128 \\
\hline
\end{tabular}

\section{Field Requirements and Credits}

The mean number of clock hours required for the total field experience for traditional students (not advanced standing) was 1,010 with a range of 720 to 1,380. Two respondents clearly entered fewer than the 900 hours required by CSWE. When asked their opinion about the CSWE hour requirement 20\% responded it was too few, $78 \%$ that it was appropriate, and $2 \%$ that it was too many. Those who responded that the hour requirement was too few tended to require more clock hours $(M=1081)$ than those who responded that it was appropriate $(M=994)$ or too many $(M=978)$.

The field directors reported that students receive a mean of 13.4 credits for their total field experience with a range of 0 to 28 . Although the one program reporting zero credits was an unusual response, low numbers of credit hours were not, as one reported three credits and two reported four. Twenty eight programs reported giving students ten or fewer credit hours for the total field experience. There was a weak and marginally significant correlation between number of credits given for the total field experience and the number of clock hours required $(r=.173, p=.056$.) A case could be made for this being a one-tailed test, in which case the p-value would be .023. Despite the correlation there was a wide range of credit given for similar effort. For example the nine programs that required 1,200 or more clock hours of field and did not separate field and seminar credit hours had a range of credits from 14 to 28 . The modal number of clock hours 
required for field was $900(n=26)$, and those 26 programs awarded from eight to 24 credit hours for the total field experience $(M=13.1, S D=3.9)$. The ratio of academic credit hours to field clock hours was computed by dividing academic credit hours by field clock hours. The range of this ratio went from one academic credit hour per 37.5 field clock hours to one academic credit hour per 306.7 field clock hours. The mean of this ratio was one academic credit hour per 86.3 field clock hours.

\section{Field Office Resources}

The number of students reported in placement during the past year ranged from 10 to $800(M=169.6, S D=164.5)$. The number of full time equivalent employees (FTEs) dedicated to field coordination ranged from .25 to eight and an outlier of $20(M=2.6$, SD = 2.6). The program with 20 FTEs reported 168 students in placement (it is possible they mistakenly included liaisons when replying to this item). The program with 800 students in placement reported five FTEs dedicated to field coordination. Although the relative resources of these two particular programs may not seem equitable, the overall relationship between the number of students and FTEs had a medium strength correlation ( $r=.332, p<.001)$. When asked about institutional support for the field component, 58\% agreed it was adequate, $17 \%$ were neutral, and $24 \%$ disagreed it was adequate. When asked about institutional financial support for the field component, $49 \%$ agreed it was adequate, $17 \%$ were neutral, and $34 \%$ disagreed it was adequate. The ratio of students to field coordination FTEs was computed. This new variable had a mean of 84:1 (i.e. 84 field students to one field coordination FTE), a range of 7:1 to 240:1, and an outlier of 640:1. (See Table 3) It was suspected that field directors of programs with a higher ratio of students per employee would perceive their institution was more supportive. This ratio was tested for correlation with the field director's perception of institutional support to explore if better staffed field offices had directors who perceived greater institutional support. It did not reach statistical significance. This ratio was then correlated with the field director's perception of institutional financial support and found to have a weak though statistically significant relationship $(r=.186, p=.035)$.

Qualitative data were solicited by asking respondents if there was anything else they could tell us about their program or field education in general. The most common theme was a lack of resources, which was cited by nine respondents, with one saying the lack of resources was so dire that it caused some students not to be visited at their placements each semester. Two respondents said that field is undervalued while one said that their field program is highly valued. Two field directors said it was difficult finding field instructors in rural areas. One said "CSWE must mandate/specify an appropriate level of support for field if it is to be the signature pedagogy." Other comments were idiosyncratic and covered a wide range of issues. 


\section{DISCUSSION}

Most programs were diligent in matching students with an appropriate placement. Only one program had neither a pre-placement questionnaire, pre-placement field office interview, nor field instructor interview. The activity that is the most time consuming for the field office is the pre-placement interview, and while it is the least utilized of the three pre-placement activities, it is still conducted by $79 \%$ of responding programs. This willingness by field directors to invest time in the interview process reflects the importance placed on an appropriate field placement match. The least time-consuming activity for the field office is to have the student interview with the field instructor, reported by $95 \%$ of programs. Although this may be time consuming for the field instructor, the benefits of this interview far outweigh the effort involved. The consequences for the field instructor and agency of having a poorly performing student or a student who is a poor match for the field agency are high as it is the field instructor and agency that bear the day to day responsibility of providing an educational environment for the student while at the same time protecting their clients. It is also in the student's interest to participate in a screening interview to ensure that the placement offers a potential good fit because "...the selection, once made, must be lived with unless the circumstances are exceptional” (Collins, Thomlison, \& Grinnell, 1992, p. 37).

Almost all programs offer both field orientation and training, and all offer at least one or the other. CSWE (2008) requires that both services be offered, but does not say that programs must require field instructors to attend. Over half of respondents reported going beyond offering orientation and training by making attendance required. Enforcement of this requirement is problematic. Of those who require orientation or training, only a third report there are consequences for field instructors who do not attend, including not placing students with those field instructors. Many programs may have trouble recruiting and retaining field instructors and are thus reluctant to enforce consequences for not attending. A field instructor may attend orientation or training because it was presented as required, but later meet other field instructors who forwent the training and suffered no consequences. If a program presents orientation or training to field instructors as required but does not enforce it, then the reputation of the program is reduced. Whether or not a program can enforce consequences may be a factor of how many placements are available in the area and how well staffed the field office is. A lack of qualified field instructors has been identified as a concern by Raskin, Skolnik, and Wayne (1991). A dearth of available instructors limits the ability to impose sanctions when program requirements are not met.

The field seminar provides an opportunity for students to discuss their practicum experiences and to integrate the learning with classroom courses (Collins et al., 1992; Mary \& Herse, 1992). In the current study, most programs (81\%) reported providing field seminars for students. If a program does not have a seminar, it is unclear where such integration would take place. At one of the author's former institutions there was no seminar, but practice classes were asked to devote time to discussing relevant field issues. This was not ideal because not all instructors did so equally, and some included little or no such discussion. When such discussions were held, it was not done with knowledge by the instructor of the student's placement as it would be in the case of a seminar leader 
who was also the liaison. A field seminar setting also allows for the development of greater trust if there are sensitive issues that need to be processed, and this function of professional support is the most common objective of seminars as previously reported by both students and faculty (Mary \& Herse). Of the programs in the current study that offer a seminar, $72 \%$ reported that field liaisons were also seminar leaders, a model that seems best at providing the integration purpose of the seminar. The role of a field liaison is to provide a crucial "bridge" between the school and the field site, and is enhanced when liaisons act as seminar leaders. Not only do the liaisons then have a more intimate sense of the placement, they are able to identify concerns and address them with more immediacy when they have regular contact with the students in the seminar setting. The large number of programs that rely on adjuncts for liaisons and seminar leaders is not surprising given the trend in much of academia to reduce costs by relying on contingent faculty (Thornton, 2008). However, adjunct faculty by its very nature have a temporal and less visible presence within schools of social work. Ensuring the quality and consistency of their work with students poses a greater challenge than working with regular faculty members. More research is indicated as how to best integrate the field and classroom experience, whether through the use of an integrative seminar or other means, and how to best provide this instruction.

Of programs that had field seminars, academic credit was given for field seminar separate from field placement hours $38 \%$ of the time. This arrangement allows for a clearer delineation of responsibility between the seminar and field, especially when academic assignments are part of the seminar. In those cases where the seminar is seen as a process group with no readings or assignments outside the seminar, then having it credited as part of the field seems appropriate. This latter pattern more closely matches the purpose of seminar as described by Collins et al. (1992). If there are readings and written assignments, the field seminar takes on the air of a classroom and runs the risk of those activities becoming more valued than the processing of field issues, which may then be neglected. The nature of field seminars could be the focus of future research.

There were a variety of ways in which liaison and seminar leaders were credited for their work, with considerable variation in whether they were given teaching credits for seminar and liaison work together or separately, how many teaching credits were granted, and how many field visits were required, all of which bring up issues of equity and fairness. As they did for the faculty, the programs also show much variation in how students are credited for the field experience. There was considerable variation in the number of placement hours required and great variation in the number of credits given to students for similar effort. Some students received many times more academic credit hours for the same number of field clock hours. These differences in programs for both students and faculty may mean richness in the variety of programs with unique emphases and approaches. It also raises issues of quality standards as some programs are more or less demanding than others yet all result in a MSW degree from a CSWE accredited institution. For faculty it means that some will have more tasks and less time to complete them.

Both qualitative and quantitative data indicate that many programs are struggling financially and in terms of perceived institutional support. In some cases the respondents 
may have been answering from a sense of felt deprivation when in fact the program has the resources to operate adequately. In other instances these results may indicate true cases of underfunding to the extent that basic operations are not possible, as in the case of the field director who said that some field visits are not made because of a lack of resources. In survey research it will always be impossible to definitively determine the level of subjectivity in responses to items like this. However the number of respondents claiming insufficient institutional support indicates a pattern of underfunding that is too widespread to be easily dismissed.

\section{RECOMMENDATIONS/CONCLUSIONS}

This paper presents general data on how field programs implement the field component. Field program directors can now use these data to inform their own implementation choices. There was a wide variation in program characteristics, reflecting a wide range of requirements, programs, and credits. The extent of the variation is large enough to raise questions regarding the provision of an equitable standard for MSW candidates enrolled in CSWE accredited programs. Do the current CSWE guidelines ensure that field experiences are of comparable quality across institutions and that they provide the type of baseline competencies as are required in core curriculum courses in the classroom? CSWE must strike a balance between mandating uniformity and allowing programs to develop in ways that seem best suited for their institution and community. If the balance goes too far toward program self-determination, then inequity between programs becomes an issue. There is currently such variety between programs in the most basic structures and requirements that field placements may vary widely by quality and degree of supervision. This can mean that students in different schools might all fulfill the requirements of the field practicum yet come out unequally prepared, not just differently prepared. The current research indicates that when programs are left to themselves to implement policy they may do so with varying degrees of proficiency. It may be time for CSWE to mandate some basic level of performance for field programs. Reasonable first steps could include: to require at least one field visit per semester, to require an expressed plan for the integration of practice and theory for those programs that do not have a field seminar, and to set a minimum target of attendance by field instructors in orientation and training. There should also be consideration of mandating some level of basic equity of student experience between programs. For this a reasonable first step could include requiring at least one academic credit hour for every 80 hours of field.

Conversely, too stringent a set of requirements leaves little leeway in designing field programs that fit the individual needs of schools and the communities in which they are located. As field placement options decrease as a result of constricted budgets and staffing, and the resources within field programs is limited, there will always be the need to work creatively within the boundaries faced by field personnel. For this reason, although more specific guidelines are needed, such guidelines should be limited in number. The provision of best practice recommendations could offer guidance to programs while allowing them the discretion that they need to function effectively. 
During the process of conducting this research the authors became aware of potential directions for future research in this area. Further research is needed to explore if and how differences in the structure of the field practicum impacts learning outcomes. Do programs with field seminars better prepare students than those that do not? Is it an advantage when field liaisons also lead field seminars? Do hour requirements impact the development of basic competencies? Additional areas of exploration include the extent of use and the benefit or detriment of employment-based field placements, and the content that field program directors include in field instructor orientation and training. This paper's description of current practices is only a first step. Empirically comparing common field practices on valid, reliable, and commonly agreed upon outcome measures will provide us with the next level of understanding.

\section{References}

Bedard, L. E., (1998). A national survey of social work field placement directors. Dissertation Abstracts International, 59, 955-A. (ISSN 0419-4209).

Berg-Weger, M., Rochman, E., Rosenthal, R., Sporleder, B., \& Birkenmaier, J. (2007). A multi-program collaboration in field education. Social Work Education, 26, 20-34. doi:10.1080/02615470601036492

Bogo, M. (2005). Field instruction in social work: A review of the research literature. The Clinical Supervisor, 24, 163-193. doi:10.1300/J001v24n01_09

Bogo, M., \& Vayda, E. (1998). The practice of field instruction in social work: Theory and practice. NY: Columbia University Press.

Brownstein, C. (1989). Practicum Issues: A Placement Planning Model. In M. S. Raskin (Ed.), Empirical studies in field instruction (pp. 93-104). NY: The Haworth Press.

Burke, S. G., Condon, S., \& Wickell, B. (1999). The field liaison role in schools of social work: A break with the past. The Clinical Supervisor, 18, 203-210. doi:10.1300/J001v18n01_13

Collins, D., Thomlison, B., \& Grinnell Jr., R. M. (1992). The social work practicum: A student guide. Itasca, IL: Peacock Publishers.

Council on Social Work Education (2008). Educational policy and accreditation standards. Alexandria, VA: Author. Available online at http://www.cswe.org/CSWE/

Dettlaff, A. J. (2003). From mission to evaluation: A field instructor training program. Alexandria, VA: Council on Social Work Education.

Dettlaff, A. J., \& Dietz, T. J. (2004). Making training relevant: Identifying field instructors' perceived training needs. The Clinical Supervisor, 23, 15-31. doi:10.1300/J001v23n01_02

Frumkin, M., \& Lloyd, G. A. (1995). Social work education. In R. L. Edwards, (Ed.), Encyclopedia of social work (19 ${ }^{\text {th }}$ ed., Vol. 3, pp. 2238-2247). Washington, DC: NASW Press. 
Kilpatrick, A. C., \& Holland, T. P. (1993). Management of the field instruction program in social work education. Journal of Social Work Education, 7, 123-136. doi:10.1300/J067v07n01_10

Ligon, J., \& Ward, J. (2005). A national study of the field liaison role in social work education programs in the United States and Puerto Rico. Social Work Education, 24, 235-243. doi:10.1080/0261547052000333153

Lipsky, M. (1980). Street-level bureaucracy: Dilemma of the individual in public services. NY: Russell Sage Foundation.

Mary, N. L., \& Herse, M. H. (1992). What do field seminars accomplish? Student and instructor perspectives. Journal of Teaching in Social Work, 6, 59-73. doi:10.1300/J067v06n02_06

McChesney, M. (1999). Agency-based social work field instructor orientation and training. Dissertation Abstracts International, 60, 551-A. (ISSN 0419-4209).

Raskin, M., \& Blome, W. W. (1998). The impact of managed care on field instruction. Journal of Social Work Education, 34, 365-374.

Raskin, M., Skolnik, L., \& Wayne, J. (1991). An international perspective of field instruction. Journal of Social Work Education, 27, 258-270.

Raskin, M., Wayne, J., \& Bogo, M. (2008). Revisiting field education standards. Journal of Social Work Education, 44, 173-188. doi:10.5175/JSWE.2008.200600142

Rogers, G. (1996). Training field instructors British style. Journal of Social Work Education, 32, 265-276.

Rubin, A., \& Babbie, E. (2001). Research methods for social work. Belmont, CA: Wadsworth.

Scannell, J. J., \& Simpson, K. (1996). Shaping the college experience outside the classroom. Rochester, NY: University of Rochester.

Skolnik, L. (1989). Field instruction in the 1980's - Realities, issues, and problemsolving strategies. In M. S. Raskin (Ed.), Empirical studies in field instruction (pp. 47-75). NY: The Haworth Press.

Thornton, S. (2008). "Where are the priorities?: The annual report on the economic status of the profession, 2007-2008. Academe, 94(2), 8-34.

Zanville, H., \& Markwood, R. (1982). A Casebook on practice in internship education. Boulder, CO: Western Interstate Commission for Higher Education.

\section{Author note:}

Address correspondence to: Bruce Dalton, Department of Social Work, Box 70645, Johnson City, TN 37614-1702. Email: DALTON@mail.etsu.edu 